\title{
Main Chain Noncentrosymmetric Hydrogen Bonded Macromolecules Incorporating Aniline, Alkanol, and Alkanoic Acid Hydrogen Bond Donors
}

\author{
Jeremy R. Wolf ${ }^{1,2}$ \\ ${ }^{1}$ Southern Illinois University Carbondale, Carbondale, IL 62901, USA \\ ${ }^{2}$ ABC Laboratories, Columbia, MO 65202, USA \\ Correspondence should be addressed to Jeremy R. Wolf; wolfchem@hotmail.com
}

Received 22 November 2013; Accepted 25 March 2014; Published 27 April 2014

Academic Editor: Jean-Marc Saiter

Copyright (C) 2014 Jeremy R. Wolf. This is an open access article distributed under the Creative Commons Attribution License, which permits unrestricted use, distribution, and reproduction in any medium, provided the original work is properly cited.

The syntheses and characterization of three noncentrosymmetric main chain hydrogen bonded macromolecules which incorporate aniline, alkanoic acid, and alkanol hydrogen bond donor units are reported. These macromolecules participate in weak intermolecular hydrogen bonding as demonstrated using attenuated total reflectance (ATR) FTIR. The phase transitions of these macromolecules depend on the identity of the hydrogen bond donor.

\section{Introduction}

Poled organic thin films are technologically useful materials [1-9] which have several advantages over traditional inorganic crystals including ease of processing [10], larger second order susceptibilities [11], an intrinsically low dielectric constant [10], and significantly faster responses [1215]. Our approach to poled organic films involves surfaceinduced polar alignment of main chain noncentrosymmetric hydrogen bonded liquid crystalline macromolecules [16]. We have previously synthesized several main chain noncentrosymmetric hydrogen bonded macromolecules (Table 1) [16], and while several of these macromolecules possess liquid crystalline phases, the melting points of these macromolecules are very high and they exhibit poor solubilities in organic solvents [16-20].

In several of our studies, we found that replacing a benzoic acid hydrogen bond donor group with a weaker hydrogen bond donor (such as a $\mathrm{OH}$ group) in our macromolecules resulted in a large melting point depressions and increased solubility in organic solvents $[19,20]$ presumably due to the weaker donor-acceptor hydrogen bonding. Alkanoic acids, alkanols, and aniline are all weaker hydrogen bond donors than their benzoic acid or phenol analogs [21], therefore incorporating these hydrogen bond donors into our noncentrosymmetric hydrogen bonded macromolecules should result in lower melting points and increased solubility. In this paper, we report the synthesis and characterization of main chain noncentrosymmetric hydrogen bonded macromolecules incorporating alkanoic acid, alkanol, and aniline hydrogen bond donors and stilbazole acceptors.

\section{Experimental Section}

2.1. Materials. All chemicals were purchased from Fisher or Aldrich chemical company and used as received. Tetrahydrofuran (THF) was distilled over sodium-benzophenone under an argon atmosphere. Chromatography was performed using Sorbent Technology 60 angstrom, 63-200 $\mu \mathrm{m}$ mesh silica (10940-25). Thin layer chromatography was performed using Whatman flexible plates with $250 \mu \mathrm{m}$ layer of fluorescent silica gel $\left(\mathrm{UV}_{254}\right)$ or EM Science glass TLC plates $\left(60 \mathrm{~F}_{265}\right)$. All final products were dried at appropriate temperatures (below their melting and/or decomposition temperatures) in a Napco E-series 5831 vacuum oven prior to analysis.

2.2. Model Mixtures. A standard procedure for making model mixtures was as follows. One component was weighted 
TABLE 1: First generation noncentrosymmetric main chain hydrogen bonded macromolecules.

\begin{tabular}{lccccc}
\hline & & & & \\
\hline \\
\hline
\end{tabular}

${ }^{*}$ Polymer possesses a liquid crystalline phase.

into a glass vial. The required amount of the other compound (to obtain the desired mole ratio) was weighted into the same vial. The content of the vial was heated in a silicon oil bath until both components were visibly melted. The vial was removed from the oil bath and the mixture was allowed to crystallize (at room temperature). The melting/crystallization sequence was repeated two additional times and the resulting mixture was analyzed.

2.3. Measurements. Proton $(300 \mathrm{MHz})$ and carbon 13 $(75 \mathrm{MHz})$ nuclear magnetic resonance spectra were acquired using a Varian VXR 300 wide bore instrument and processed using either VNMR or Mestrec software. Infrared spectroscopy was performed on Thermo-Nicolet Nexus 670-FTIR using an Avatar multibounce HATR accessory; spectra were processed using OMNIC software. Mass spectra were acquired by the staff at the Mass Spectroscopy Lab at University of Illinois, Urbana, IL. Differential scanning calorimetry was performed on a Mettler Toledo DSC 821e equipped with a Julabo FT 900 cooling unit using heating and cooling rates of $10^{\circ} \mathrm{C} / \mathrm{min}$ unless otherwise stated; all reported transition temperatures are from the second cycle of a DSC scan unless otherwise stated. All DSC transition temperatures reported are the midpoints of the transition; the enthalpies of the transitions are reported in parentheses following the transition temperature. Polarized optical microscopy was performed on an Olympus BXP polarizing microscope equipped with and Instec HCS400 heating stage; heating and cooling rates used varied between 1 and $5^{\circ} \mathrm{C} / \mathrm{min}$.

2.4. Experimental Procedures for Synthesizing All Macromolecules and Intermediates. The syntheses of macromolecules 1-5 were described by our group previously [17-20]. Compounds 6, 8, 12, and 15 were synthesized according to the literature procedures [21-24].

tert-Butyl [4-(10-Chlorodecyloxy)-phenyl]-carbamate (7). Sodium hydride $(1.085 \mathrm{~g}, 47.2 \mathrm{mmol})$ was placed in a roundbottomed flask equipped with a condenser and argon purge.
Anhydrous DMF $(20 \mathrm{~mL})$ was added via syringe. Solid compound $6(3.002 \mathrm{~g}, 14.3 \mathrm{mmol})$ was slowly added to the flask; this mixture was stirred for 30 minutes. 1,10-Dichlorodecane $(9.0 \mathrm{~mL}, 42.6 \mathrm{mmol})$ was added to the flask via syringe and the mixture was stirred at room temperature for 30 minutes. Water $(50 \mathrm{~mL})$ was added to the reaction mixture and the solution was extracted with ethyl acetate $(5 \times 50 \mathrm{~mL})$. The extract was washed with brine and dried over $\mathrm{MgSO}_{4}$, and the crude product was adsorbed onto silica. The product was purified via column chromatography $(85 / 15 \mathrm{Hex} / \mathrm{EtOAc})$; evaporation of the solvent yielded $0.751 \mathrm{~g}(14 \%)$ of 7 as a white solid: $R_{f}=0.39$ (85/15 Hex/EtOAc); ${ }^{1} \mathrm{H}$ NMR $(300 \mathrm{MHz}$, $\left.\mathrm{CDCl}_{3}\right) \delta 1.44(\mathrm{~m}, 22 \mathrm{H}), 1.74(\mathrm{~m}, 2 \mathrm{H}), 3.53(\mathrm{t}, J=6.83,2 \mathrm{H})$, $3.91(\mathrm{t}, J=6.27,2 \mathrm{H}), 6.34(\mathrm{bs}, 1 \mathrm{H}), 6.83(\mathrm{~d}, J=9.41,2 \mathrm{H})$, and $7.26(\mathrm{~d}, J=10.25,2 \mathrm{H}) ;{ }^{13} \mathrm{C}$ NMR $\left(75 \mathrm{MHz}, \mathrm{CDCl}_{3}\right)$ $\delta 25.98,26.84,28.34,28.84,29.25,29.31,29.35,29.41,29.69$, $32.61,45.16,68.26,114.83,120.53,131.21$, and 155.20; Mass Spec $\mathrm{M}^{+}=383.3$ Calc.: 383.2227 .

tert-Butyl (4-10-[4-(2-Pyridin-4-yl-vinyl)-phenoxy]-decyloxyphenyl)-carbamate (9). Compound 7 (0.674 g, $1.8 \mathrm{mmol})$, compound $8(0.311 \mathrm{~g}, 1.6 \mathrm{mmol})$, and $\mathrm{K}_{2} \mathrm{CO}_{3}(0.764 \mathrm{~g}$, $5.5 \mathrm{mmol}$ ) were placed in a round-bottomed flask equipped with a condenser and argon purge. Anhydrous DMF $(20 \mathrm{~mL})$ was added via syringe and the reaction was heated to $120^{\circ} \mathrm{C}$ for 7 hours; the mixture was cooled; and water $(100 \mathrm{~mL})$ was added. The solution was extracted with EtOAc $(7 \times 50 \mathrm{~mL})$; the extract was washed with brine and dried over $\mathrm{MgSO}_{4}$; and the crude product was adsorbed onto silica. The product was purified by column chromatography (60/40 EtOAc/Hex); evaporation of the solvent yielded $0.412 \mathrm{~g}(48 \%)$ of 9 as a yellow solid: $R_{f}=0.49(60 / 40 \mathrm{EtOAc} / \mathrm{Hex}) ;{ }^{1} \mathrm{H}$ NMR $\left(300 \mathrm{MHz}, \mathrm{DMSO}-\mathrm{d}_{6}\right) \delta 1.38(\mathrm{~m}, 21 \mathrm{H}), 1.66(\mathrm{~m}, 4 \mathrm{H}), 3.86(\mathrm{t}$, $J=6.80,2 \mathrm{H}), 3.98(\mathrm{t}, J=6.45,2 \mathrm{H}), 6.79(\mathrm{~d}, J=8.63,2 \mathrm{H})$, $6.95(\mathrm{~d}, J=8.78,2 \mathrm{H}), 7.06(\mathrm{~d}, J=16.74,2 \mathrm{H}), 7.50(\mathrm{~m}, 6 \mathrm{H})$, $8.49(\mathrm{~d}, J=6.02,2 \mathrm{H})$, and $9.11(\mathrm{bs}, 1 \mathrm{H}) ;{ }^{13} \mathrm{C}$ NMR $(75 \mathrm{MHz}$, $\mathrm{CDCl}_{3}$ ) $\delta 25.47,28.16,28.62,28.74,28.92,67.50,78.61,114.38$, $114.74,119.62,120.57,123.40,128.53,128.60,132.46,132.68$, $144.64,152.91,153.86$, and 159.19.

4-\{10-[4-(2-Pyridin-4-yl-vinyl)-phenoxy]-decyloxy\}-phenylamine (10). Compound 9 (0.175 g, $0.3 \mathrm{mmol})$, THF $(18 \mathrm{~mL})$, and $\mathrm{MeOH}(10 \mathrm{~mL})$ were combined in a round-bottomed flask. Concentrated $\mathrm{HCl}(10 \mathrm{~mL})$ was slowly added to the flask and the mixture was allowed to stir for $16 \mathrm{hr}$ at room temperature. The solution was neutralized $(\mathrm{pH}=7)$ with solid $\mathrm{NaHCO}_{3}$ and the precipitate was collected by vacuum filtration; the solid so obtained was dried in the oven affording $0.098 \mathrm{~g}(66 \%)$ of $\mathbf{1 0}$ as a tan solid: ${ }^{1} \mathrm{H}$ NMR $\left(300 \mathrm{MHz}\right.$, DMSO- $\left.\mathrm{d}_{6}\right) \delta 1.32(\mathrm{~m}, 12 \mathrm{H}), 1.71(\mathrm{~m}, 4 \mathrm{H}), 3.82(\mathrm{~d}$, $J=6.74,2 \mathrm{H}), 4.02(\mathrm{~d}, J=6.30,2 \mathrm{H}), 4.41(\mathrm{bs}, 2 \mathrm{H}), 6.59(\mathrm{~m}$, $4 \mathrm{H}), 6.96(\mathrm{~m}, 3 \mathrm{H}), 7.43(\mathrm{~m}, 5 \mathrm{H})$, and $8.50(\mathrm{~d}, J=5.31,2 \mathrm{H})$; ${ }^{13} \mathrm{C}$ NMR (75 MHz, DMSO-d d $_{6} \delta 26.11,26.21,29.31,29.37$, $29.48,29.66,68.64,69.27,71.18,115.77,116.70,116.53,121.27$, $124.43,129.15,129.61,133.49,142.62,145.48,150.17,150.53$, and 160.11; Mass Spec $\mathrm{M}^{+}=445.2$ Calc.: 444.2777.

10-[4-(2-Pyridin-4-yl-vinyl)-phenoxy]-decan-1-ol (11). Compound $8(0.303 \mathrm{~g}, 1.5 \mathrm{mmol}), \mathrm{K}_{2} \mathrm{CO}_{3}(0.644 \mathrm{~g}, 4.7 \mathrm{mmol})$, 

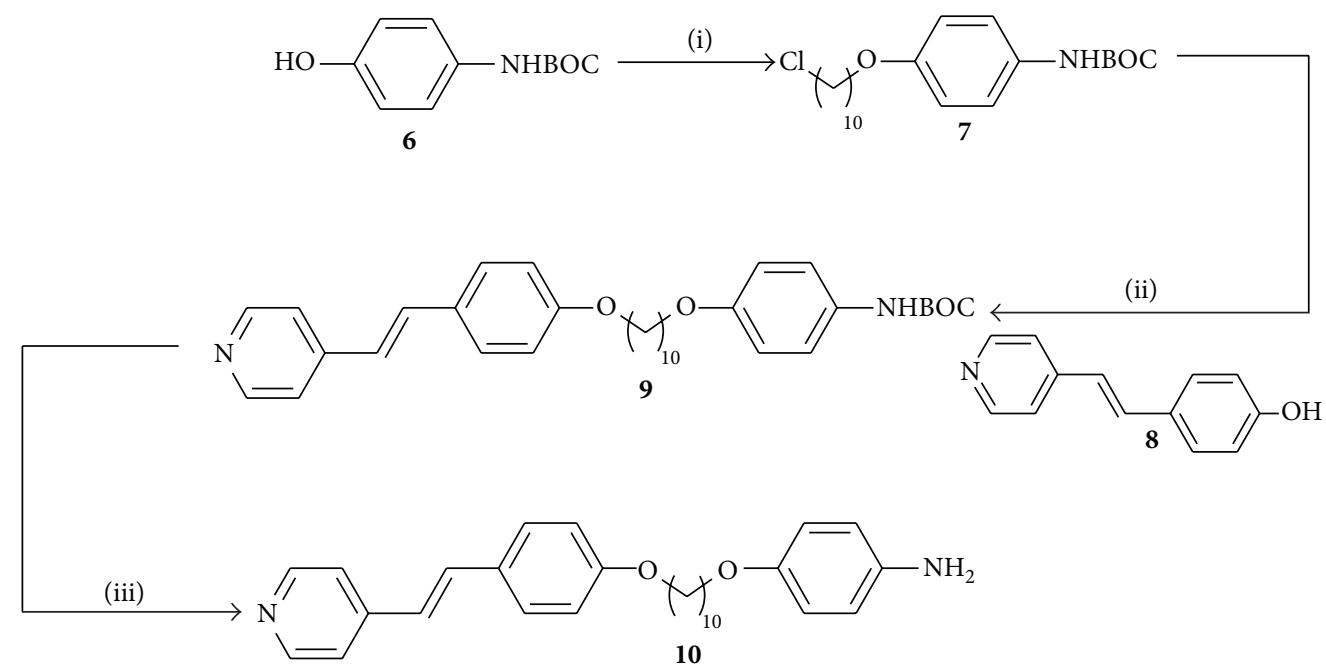

Scheme 1: Synthetic scheme for obtaining macromolecule 10: (i) $\mathrm{NaH}, 1,10$-dichlorodecane; (ii) $\mathrm{K}_{2} \mathrm{CO}_{3}$, 3; (iii) $\mathrm{HCl}$, THF.
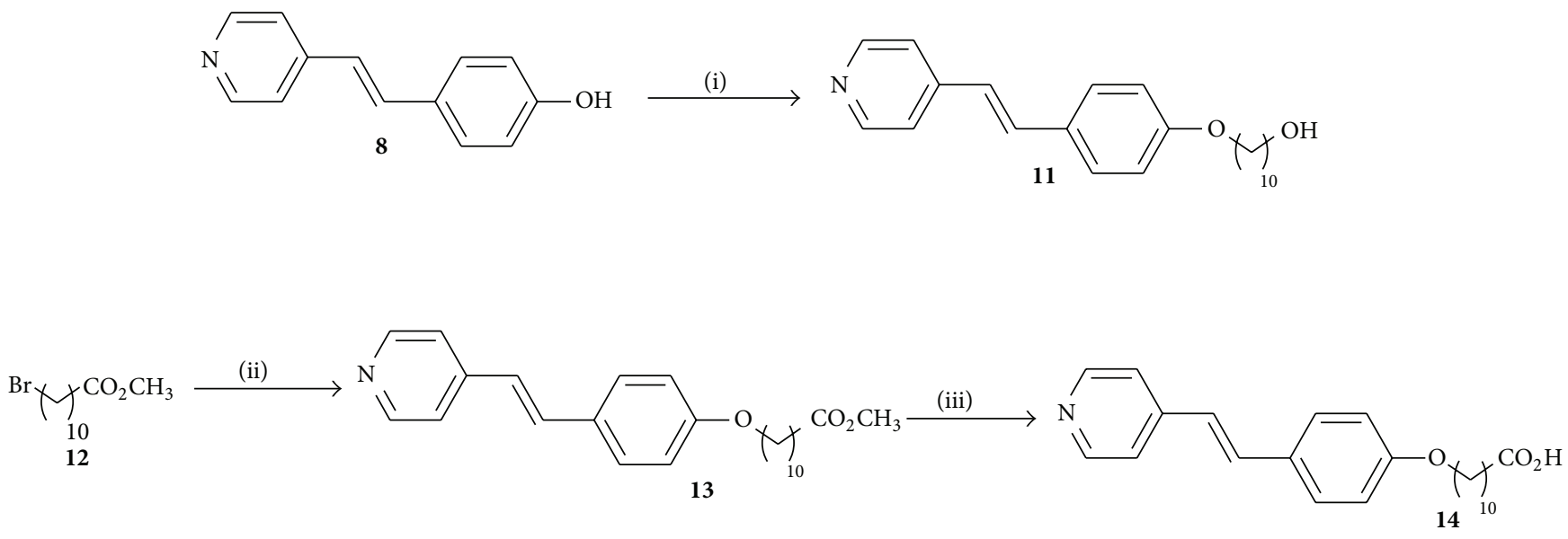

Scheme 2: Synthetic schemes for obtaining macromolecules 6 and 9: (i) 10-chlorodecanol, $\mathrm{K}_{2} \mathrm{CO}_{3}$; (ii) 8, $\mathrm{K}_{2} \mathrm{CO}_{3}$; (iii) $\mathrm{NaOH}$, THF, MeOH.

and 1-chloro-10-decanol $(0.28 \mathrm{~mL}, 1.4 \mathrm{mmol})$ were combined in a round-bottom flask equipped with a condenser and argon purge. Dry DMF $(10 \mathrm{~mL})$ was added via syringe and the solution was heated to $120^{\circ} \mathrm{C}$ for 24 hours and then cooled to room temperature. Water $(100 \mathrm{~mL})$ was added; the solution was extracted with ethyl acetate $(7 \times 50 \mathrm{~mL})$; the acetate layer was dried over $\mathrm{MgSO}_{4}$; and the crude product was evaporated onto silica gel. The product was purified via column chromatography using graduated elutions from 60/40 to 40/60 (Hex/EtOAc); evaporation of solvent afforded pale yellow solid. The solid so obtained was recrystallized in methanol to afford $80 \mathrm{mg}(15 \%)$ of $\mathbf{1 1}$ as a white powder: $R_{f}=0.43$ (60/40 Hex/EtOAc); ${ }^{1} \mathrm{H}$ NMR (300 MHz, DMSO$\left.\mathrm{d}_{6}\right) \delta 1.36(\mathrm{~m}, 16 \mathrm{H}), 1.71(\mathrm{t}, J=6.77,2 \mathrm{H}), 3.99(\mathrm{t}, J=11.07$, $2 \mathrm{H}), 4.33(\mathrm{t}, J=4.80,1 \mathrm{H}), 6.96(\mathrm{~d}, J=8.60,2 \mathrm{H}), 7.08(\mathrm{~d}$, $J=16.61,1 \mathrm{H}), 7.50(\mathrm{~m}, 3 \mathrm{H}), 7.58(\mathrm{~d}, J=8.86,2 \mathrm{H})$, and 8.51 $(\mathrm{d}, J=5.86,2 \mathrm{H}) ;{ }^{13} \mathrm{C}$ NMR $\left(75 \mathrm{MHz}, \mathrm{DMSO}-\mathrm{d}_{6}\right) \delta 25.45$, $28.54,28.59,28.72,28.92,28.99,32.49,114.66,120.49,123.30$, $128.45,128.52,132.60,144.56,149.39$, and 149.85; Mass Spec $\mathrm{M}^{+}=353.3$ Calc.: 353.2355 .
Methyl-11-[4-(2-pyridin-4-yl-vinyl)-phenoxy]-undecanoate

(13). Compound 12 (1.915 g, $6.9 \mathrm{mmol}), \mathrm{K}_{2} \mathrm{CO}_{3}$ (2.578 g, $18.7 \mathrm{mmol})$, and compound $8(1.200 \mathrm{~g}, 6.1 \mathrm{mmol})$ were placed in a dried round-bottomed flask equipped with a condenser and argon purge; this mixture was heated to $70^{\circ} \mathrm{C}$ for 24 hours and $110^{\circ} \mathrm{C}$ for an additional 24 hours. The mixture was cooled to room temperature, water $(100 \mathrm{~mL})$ was added, and the mixture was extracted with EtOAc $(7 \times 50 \mathrm{~mL})$; the acetate extract was washed with brined and dried over $\mathrm{MgSO}_{4}$, and the crude product was adsorbed onto silica. The product was purified via column chromatography using elutions from 50/50 to $70 / 30$ (EtOAc/Hex); evaporation of the solvent afforded $0.579 \mathrm{~g}(24 \%)$ of compound 13 as an impure bright-yellow solid: $R_{f}=0.55(70 / 30 \mathrm{EtOAc} / \mathrm{Hex}) ;{ }^{1} \mathrm{H}$ NMR $(300 \mathrm{MHz}$, DMSO $\left.-\mathrm{d}_{6}\right) \delta 1.38(\mathrm{~m}, 14 \mathrm{H}), 1.69(\mathrm{t}, J=6.04,2 \mathrm{~h}), 2.26(\mathrm{t}$, $J=7.42,2 \mathrm{H}), 3.56(\mathrm{~s}, 3 \mathrm{H}), 3.98(\mathrm{t}, J=7.15,2 \mathrm{H}), 6.94(\mathrm{~d}$, $J=8.26,2 \mathrm{H}), 7.05(\mathrm{~d}, J=16.76,1 \mathrm{H}), 7.42(\mathrm{~s}, 1 \mathrm{H}), 7.49(\mathrm{~d}, J=$ $4.94,2 \mathrm{H}), 7.56(\mathrm{~d}, J=8.40,2 \mathrm{H})$, and $8.48(\mathrm{~d}, J=4.36,2 \mathrm{H})$.

11-[4-(2-Pyridin-4-yl-vinyl)-phenoxy]-undecanoic Acid (14). Compound 13 (0.579 g, $1.5 \mathrm{mmol}$ ), KOH (1.636 g, $32.7 \mathrm{mmol}$ ), 


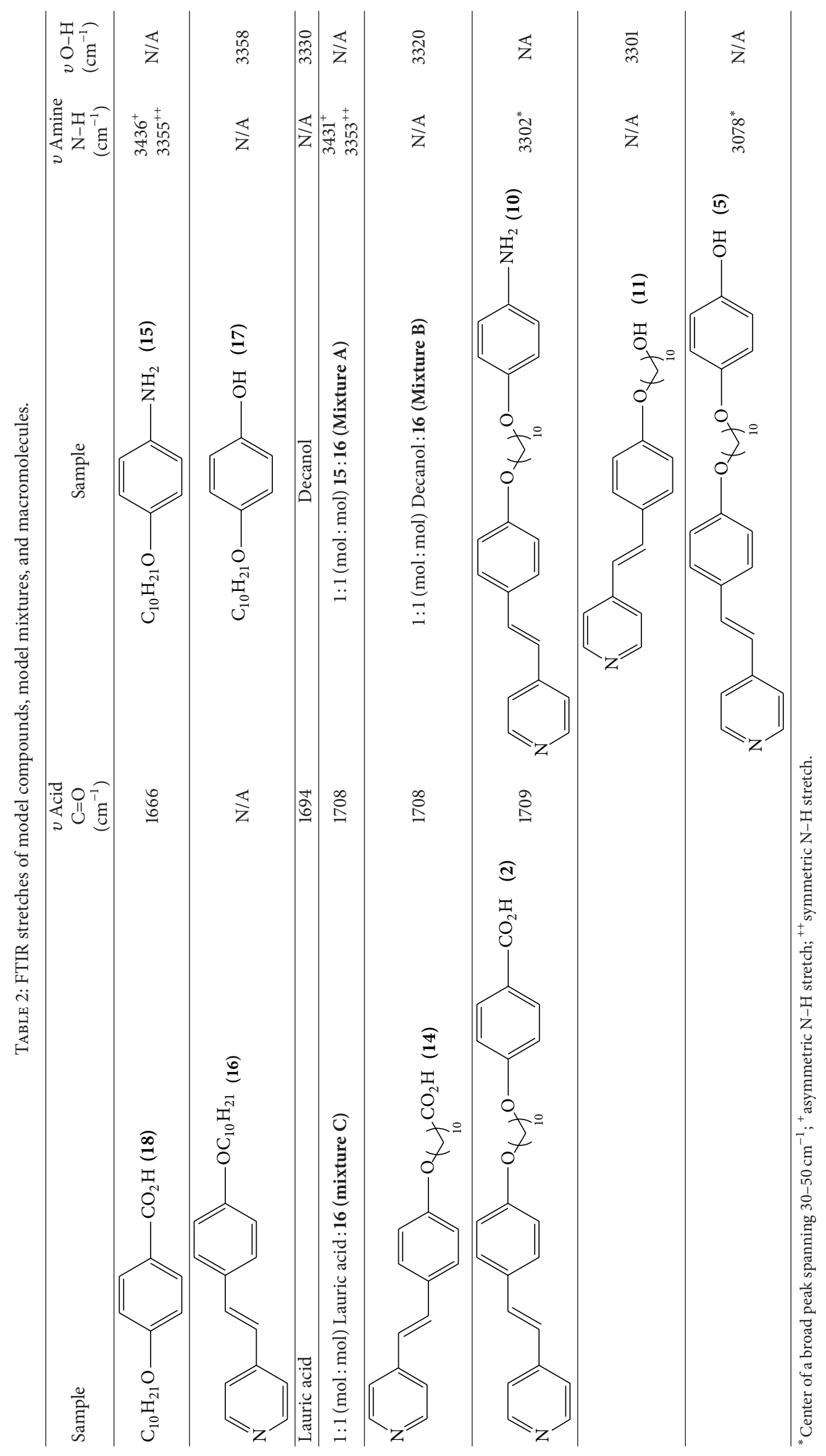


$5 \mathrm{~N} \mathrm{NaOH}(22 \mathrm{~mL})$, THF $(30 \mathrm{~mL})$, and $\mathrm{MeOH}(20 \mathrm{~mL})$ were placed in a round-bottomed flask equipped with a condenser; this mixture was refluxed for 2 days. The mixture was cooled to room temperature and neutralized $(\mathrm{pH}=7)$ with $5 \mathrm{~N} \mathrm{HCl}$; the mixture was cooled in the refrigerator. The solution was vacuum filtered and the solid so obtained was washed with water and acetone; this solid was dried in vacuum to afford $0.495 \mathrm{~g}$ (89\%) of 14 as an off-white solid: $R_{f}=0.33$ (EtOAc);

${ }^{1} \mathrm{H}$ NMR $\left(300 \mathrm{MHz}\right.$, DMSO-d $\left.{ }_{6}\right) \delta 1.36(\mathrm{~m}, 14 \mathrm{H}), 1.69(\mathrm{t}$, $J=6.38,2 \mathrm{H}), 2.16(\mathrm{t}, J=7.34,2 \mathrm{H}), 3.96(\mathrm{t}, J=6.36,2 \mathrm{H})$, $6.94(\mathrm{~d}, J=8.96,2 \mathrm{H}), 7.07(\mathrm{~d}, J=16.44,1 \mathrm{H}), 7.43(\mathrm{~s}, 1 \mathrm{H})$, $7.49(\mathrm{~d}, J=5.98,2 \mathrm{H}), 7.57(\mathrm{~d}, J=8.48,2 \mathrm{H})$, and $8.48(\mathrm{~d}$, $J=5.47,2 \mathrm{H}) ;{ }^{13} \mathrm{C}$ NMR $(75 \mathrm{MHz}$, DMSO-d 6 ) $\delta$; Mass Spec $\mathrm{M}^{+}=381.3$ Calc.: 381.2304 .

4-[2-(4-Decyloxy-phenyl)-vinyl]-pyridine (16). Compound 8 $(1.504 \mathrm{~g}, 7.6 \mathrm{mmol}), \mathrm{K}_{2} \mathrm{CO}_{3}(2.618 \mathrm{~g}, 18.9 \mathrm{mmol})$, decylbromide $(1.60 \mathrm{~mL}, 7.8 \mathrm{mmol})$, and dry DMF $(20 \mathrm{~mL})$ were combined in an oven dried round bottomed flask equipped with a condenser and an argon purge; this mixture was heated to $120^{\circ} \mathrm{C}$ for 18 hours and then cooled to room temperature. Water $(100 \mathrm{~mL})$ was added and the solution was extracted with EtOAc $(5 \times 100 \mathrm{~mL})$. The combined organic layers were washed with brine and dried over $\mathrm{MgSO}_{4}$. The crude product was purified via column chromatography using elutions from $60 / 40$ to $50 / 50$ (Hex/EtOAc). Evaporation of the solvent afforded an yellow solid, which was recrystallized twice from hexanes to afford $0.902 \mathrm{~g}(35 \%)$ of $\mathbf{1 6}$ as a pale yellow solid: $R_{f}=0.37(50 / 50 \mathrm{Hex} / \mathrm{EtOAc}) ;{ }^{1} \mathrm{H} \mathrm{NMR}\left(300 \mathrm{MHz}, \mathrm{CDCl}_{3}\right) \delta$ $0.88(\mathrm{t}, J=6.36,3 \mathrm{H}), 1.27(\mathrm{~m}, 14 \mathrm{H}), 1.79(\mathrm{t}, J=6.83,2 \mathrm{H}), 3.98$ $(\mathrm{t}, J=6.92,2 \mathrm{H}), 6.90(\mathrm{~m}, 3 \mathrm{H}), 7.26(\mathrm{~d}, J=16.49,1 \mathrm{H}), 7.34(\mathrm{~d}$, $J=6.34,2 \mathrm{H}), 7.46(\mathrm{~d}, J=8.86,2 \mathrm{H})$, and $8.54(\mathrm{~d}, J=6.32$, $2 \mathrm{H}) ;{ }^{13} \mathrm{C} \mathrm{NMR}\left(75 \mathrm{MHz}, \mathrm{CDCl}_{3}\right) \delta 14.09,22.66,26.00,29.20$, $29.23,29.37,29.55,31.87,67.16,68.12,114.82,120.60,123.56$, $128.35,132.78,145.62,150.11,154.68$, and 159.82; IR (ATR) 2918, 2851, 1590, 1514, 1256, and $1168 \mathrm{~cm}^{-1}$; MS (EI+) m/e 337 (197, $180,168,115,91$, and 62).

\section{Results and Discussion}

3.1. Synthesis of Macromolecules. The synthesis of macromolecule 10 is shown in Scheme 1. Compound 6 was reacted with 1,10-dichlorodecane to afford O-alkylated compound 7. The identity of compound 7 (as the O-alkylated product) was confirmed using a nuclear overhauser effect (NOE) NMR experiment, while the yield of compound 7 was low, extending the reaction time or increasing the temperature during the reaction resulted in an inseparable mixture of $\mathrm{N}$ alkylated and $\mathrm{O}$-alkylated products which contained little to no compound 7. Alkylation of 7 with stilbazole 8 afforded compound 9 which was deprotected using $\mathrm{HCl}$ to afford macromolecule 10 which precipitated from solution upon neutralization of the cleavage medium. Macromolecule 10 is soluble in hot DMSO $\left(120^{\circ} \mathrm{C}\right)$ and hot $\left(120^{\circ} \mathrm{C}\right) \mathrm{DMF}$ but insoluble in less polar organic solvents.

The syntheses of macromolecules 11 and 14 are shown in Scheme 2. Macromolecule 11 was synthesized in one step via basic coupling of compound 8 and 10-chlorodecanol.
Compound 12 was alkylated with stilbazole 8 to afford compound 13. Basic hydrolysis of 13 afforded macromolecule 14 , which precipitated upon neutralization of the basic cleavage medium. Macromolecule 11 is soluble in DMSO, DMF, and alcohols at room temperature, whereas the solubility of 14 is similar to that of macromolecule 10.

3.2. Hydrogen Bonding in Our Macromolecules. Solid state FTIR was used to analyze the hydrogen bonding in our noncentrosymmetric macromolecules. Select FTIR stretches for model compounds, model mixtures (which mimic the hydrogen bonding in our macromolecules), and our macromolecules are shown in Table 2. The amine $\mathrm{N}-\mathrm{H}$ peaks in model mixture $\mathrm{A}$ and macromolecule 10 are red shifted with respect to the $\mathrm{N}-\mathrm{H}$ shifts in 4-decyloxyaniline which suggest strong intermolecular hydrogen bonding in 10. In macromolecule 10 , the asymmetric and symmetric $\mathrm{N}-\mathrm{H}$ stretches merge together into one broad peak which can be attributed to the numerous possible orientations of the $\mathrm{N}-$ $\mathrm{H}$ (i.e., donor-donor or donor-acceptor) hydrogen bonds in the macromolecule. The $\mathrm{O}-\mathrm{H}$ stretches in macromolecule 11 and mixture $B$ are red shifted by $10-20 \mathrm{~cm}^{-1}$ with respect to those in 1-decanol. The magnitude of this red shift is small compared to the approximately $250 \mathrm{~cm}^{-1}$ red shift in the $\mathrm{O}-\mathrm{H}$ stretch observed when phenols form hydrogen bonds with stilbazoles $[19,20]$, which suggests relatively weak intermolecular hydrogen bonding in macromolecule 11 compared to its phenol analogue (compound 5). The $\mathrm{C}=\mathrm{O}$ stretch in macromolecule 14 is blue shifted $14 \mathrm{~cm}^{-1}$ relative to that in lauric acid. This shift is smaller than the $43 \mathrm{~cm}^{-1}$ shift between the $\mathrm{C}=\mathrm{O}$ between 13 and macromolecule 2 which suggests that the intermolecular hydrogen bonds in macromolecule 14 are weaker than those of inmacromolecule 2.

\subsection{Phase Transitions of Noncentrosymmetric Hydrogen} Bonded Macromolecules. The phase transitions of the macromolecules synthesized in this paper were characterized using Polarized Optical Microscopy (POM) and Differential Scanning Calorimetry (DSC) and are summarized in Figure 1. The melting point of macromolecule 10 is $31^{\circ} \mathrm{C}$ lower than that of the phenol analog (macromolecule 5) and $87^{\circ} \mathrm{C}$ lower than that of its benzoic acid analogue (macromolecule 2). This melting point depression can be attributed to the relatively weaker amine-stilbazole hydrogen bonding. Macromolecules 11 and 14 have crystal-crystal transitions on the heating and cooling cycles but no liquid crystalline phases. The melting points of 11 and 14 are comparable to that of 10 suggesting that (like macromolecule 10) macromolecules 11 and 14 have relatively weak intermolecular hydrogen bonding (relative to those in macromolecules 2 and 5).

\section{Conclusions}

The synthesis of three new main chain noncentrosymmetric hydrogen bonded macromolecules incorporating alkanol, alkanoic acid, and aniline donors is described. Relatively weak intermolecular hydrogen bonding is present in macromolecules 10, 11, and 14. Macromolecules 11 and 14 

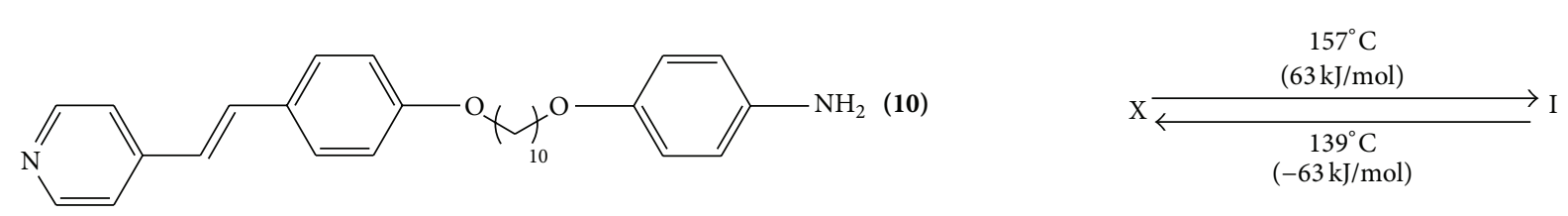
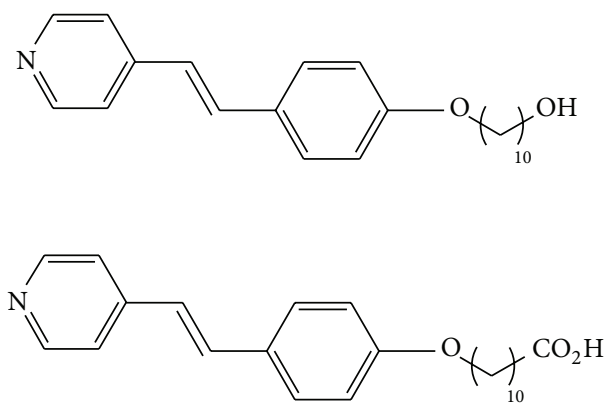

X: solid

I: isotropic
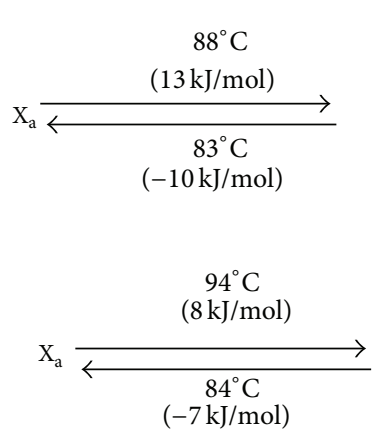

$\mathrm{X}_{\mathrm{a}}$ : crystal A

$\mathrm{X}_{\mathrm{b}}$ : crystal B

FIgURE 1: Phase transitions of macromolecules 10, 11, and 14.

both possess enantiotropic crystal $\rightarrow$ crystal transitions in addition to melting and crystallization temperatures, while macromolecule 10 only has melting and crystallization phase transitions. The phase transition temperatures of $\mathbf{1 0}, \mathbf{1 1}$, and 14 are lower than that of the phenol and benzoic acid analogues due to weaker hydrogen bonding.

\section{Conflict of Interests}

The author declares that there is no conflict of interests regarding the publication of this paper.

\section{Acknowledgments}

This paper is dedicated to the memory of Dr. Daniel J. Dyer, Professor of chemistry at Southern Illinois University, Carbondale. The author would like to thank the National Science Foundation under Grant CHE_0094195, Oak Ridge Associated Universities, the Materials Technology Center at Southern Illinois University Carbondale, and the Office of Research Development and Administration at Southern Illinois University for support of this research.

\section{References}

[1] R. A. Hann and D. Bloor, "Organic materials for non-linear optics II," in Proceedings of the 2nd International Symposium on Organic Materials for Non-Linear Optics Organised by the Applied Solid State Chemistry Group of the Dalton Division of the Royal Society of Chemistry, D. Bloor and R. A. Hann, Eds., Oxford, UK, September 1990.

[2] P. N. Butcher and D. Cotter, The Elements of Nonlinear Optics, Cambridge University, New York, NY, USA, 1990.
[3] D. V. Skobeltsyn, Nonlinear Optics, Consultants Bureau, New York, NY, USA, 1970.

[4] G. C. Baldwin, An Introduction to Nonlinear Optics, Plenum, New York, NY, USA, 1969.

[5] R. Schwödiauer, G. S. Neugschwandtner, K. Schrattbauer et al., "Preparation and characterization of novel piezoelectric and pyroelectric polymer electrets," IEEE Transactions on Dielectrics and Electrical Insulation, vol. 7, no. 4, pp. 578-586, 2000.

[6] M. C. Petty, "Molecular electronics: prospects for instrumentation and measurement science," Measurement Science and Technology, vol. 7, no. 5, pp. 725-735, 1996.

[7] J. Tsibouklis, M. Petty, M. C. Petty, and W. J. Feast, "Pyroelectric polymer structures," International Journal of Electronics, vol. 78, no. 6, pp. 1101-1105, 1995.

[8] G. Eberle, H. Schmidt, and W. Eisenmenger, "Piezoelectric polymer electrets," IEEE Transactions on Dielectrics and Electrical Insulation, vol. 3, no. 5, pp. 624-646, 1996.

[9] Q. X. Chen and P. A. Payne, "Industrial applications of piezoelectric polymer transducers," Measurement Science and Technology, vol. 6, no. 3, pp. 249-267, 1995.

[10] C. H. Bosshard, M. Bösch, I. Liakatas, M. Jäger, and P. Günter, "Second-order nonlinear optical organic materials: recent developments," in NonlInear Optical Effects and Materials, P. Günter, Ed., vol. 72 of Springer Series in Optical Sciences, chapter 3, pp. 163-299, Springer, 2000.

[11] A. Carella, A. Castaldo, R. Centore, A. Fort, A. Sirigu, and A. Tuzi, "Synthesis and second order nonlinear optical properties of new chromophores containing 1,3,4-oxadiazole and thiophene rings," Journal of the Chemical Society, Perkin Transactions 2, no. 11, pp. 1791-1795, 2002.

[12] Y. Cui, G. Qian, L. Chen, Z. Wang, J. Gao, and M. Wang, "Enhanced thermal stability of dipole alignment in inorganicorganic hybrid films containing benzothiazole chromophore," Journal of Physical Chemistry B, vol. 110, no. 9, pp. 4105-4110, 2006. 
[13] M. Jazbinsek, L. Mutter, and P. Günter, "Photonic applications with the organic nonlinear optical crystal DAST," IEEE Journal on Selected Topics in Quantum Electronics, vol. 14, no. 5, pp. 1298-1311, 2008.

[14] J. Chen, S. Marturunkalkul, L. Li, J. Kumar, and S. K. Tripathy, "Second order nonlinear optical materials," in Handbook of Conducting Polymers, pp. 727-743, CRC Press, New York, NY, USA, 1998.

[15] E. Chen and A. Murphy, Broadband Optical Modulators, CRC Press, New York, NY, USA, 2011.

[16] C. Landorf, J. Wolf, C. Li et al., "Design of polar organic liquid crystalline thin films," in Organic Thin Films for Photonic Applications, vol. 64 of Trends in Optics and Photonics Series, pp. 145-152, Optical Society of America, Washington, DC, USA, 2002.

[17] C. Landorf, J. Simpson, J. Jacobsen, and D. J. Dyer, "Design and synthesis of noncentrosymmetric organic thin films with Hydrogen bonded main chain polymers," Polymeric Materials: Science and Engineering, vol. 83, pp. 172-173, 2000.

[18] D. J. Dyer, J. Wolf, C. Li et al., "Design and synthesis of noncentrosymmetric hydrogen bonded main chain liquid crystalline polymers: towards polar order in organic thin films," Polymer Preprints, vol. 44, no. 1, p. 578, 2003.

[19] J. R. Wolf, Synthesis and characterization of noncentrosymmetric Hydrogen bonded liquid crystalline polymers [Ph.D. thesis], Southern Illinois University, 2005.

[20] J. R. Wolf, T. Zhao, C. Landorf, and D. J. Dyer, "Synthesis and characterisation of laterally substituted noncentrosymmetric main chain hydrogen-bonded polymers," Liquid Crystals, vol. 41, no. 5, pp. 721-730, 2014.

[21] L. Jongen, B. Goderis, I. Dolbnya, and K. Binnemans, "Influence of the chain length on the thermal behavior of lanthanide(III) 4alkoxybenzoates," Chemistry of Materials, vol. 15, no. 1, pp. 212217, 2003.

[22] A. R. Lapucha, "Heterocyclic analogs of stilbenes: reactions of (E)-4-azastilbenes with polymethylene dibromides," Polish Journal of Chemistry, vol. 61, no. 4-6, pp. 563-567, 1987.

[23] D. S. Clyne and L. Weiler, "The synthesis of 14-membered macrocyclic ethers," Tetrahedron, vol. 55, no. 48, pp. 1365913682, 1999.

[24] R. M. Meudtner, M. Ostermeier, R. Goddard, C. Limberg, and S. Hecht, "Multifunctional "clickate" as versatile extended heteroaromatic building blocks: efficient synthesis via click chemistry, conformational preferences, and metal coordination," Chemistry - A European Journal, vol. 13, no. 35, pp. 98349840, 2007. 

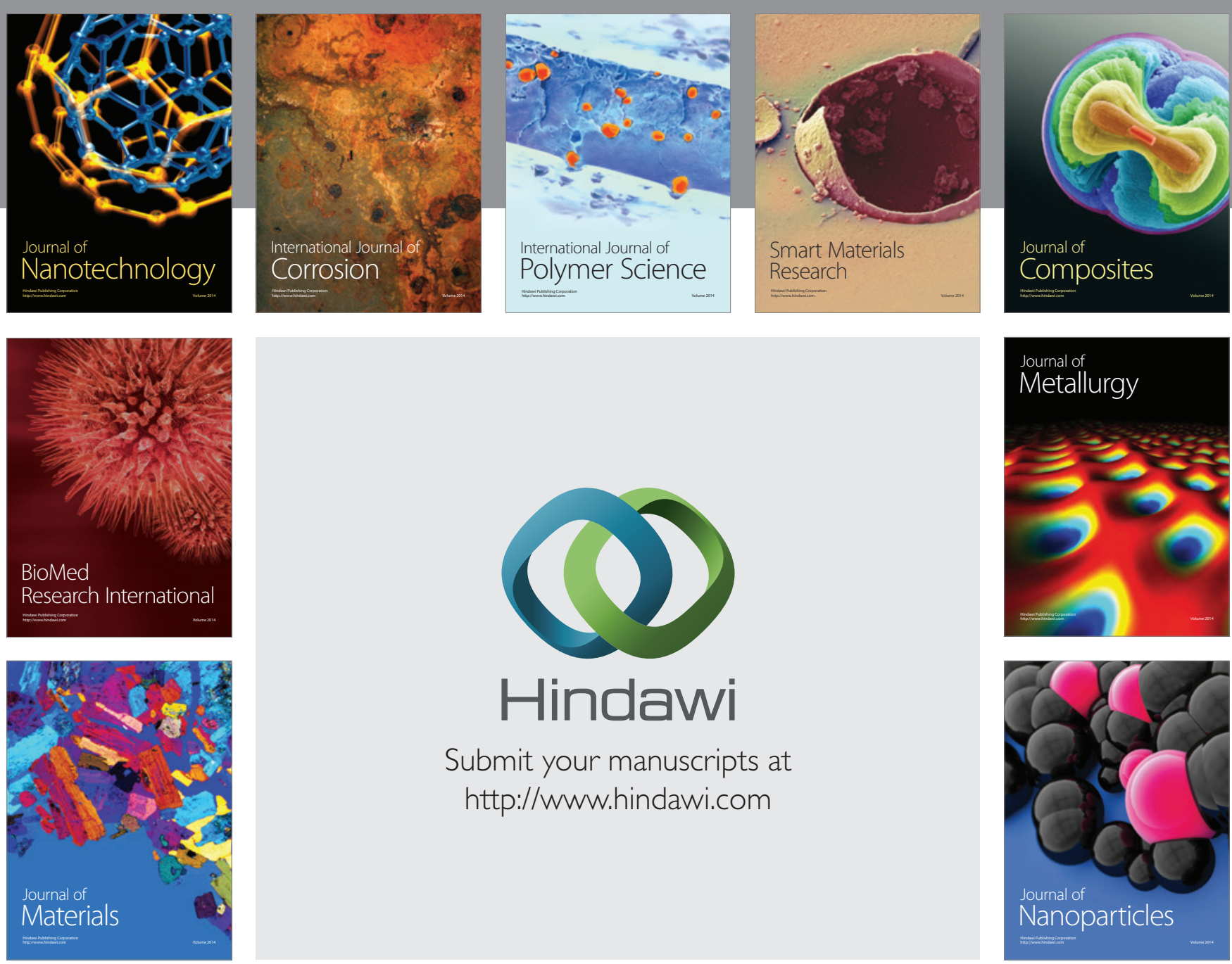

Submit your manuscripts at http://www.hindawi.com
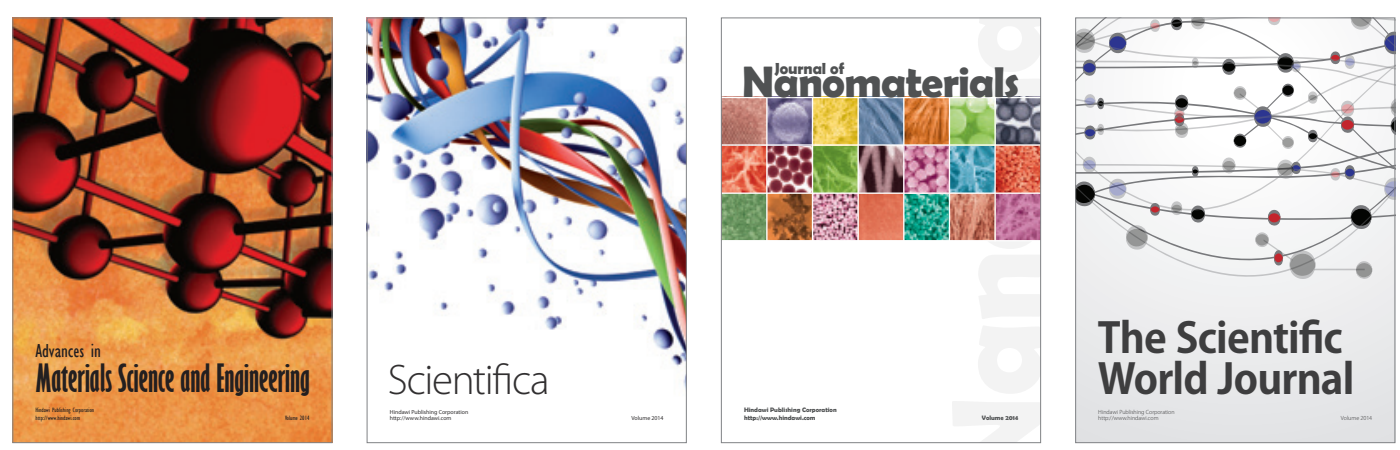

\section{The Scientific World Journal}
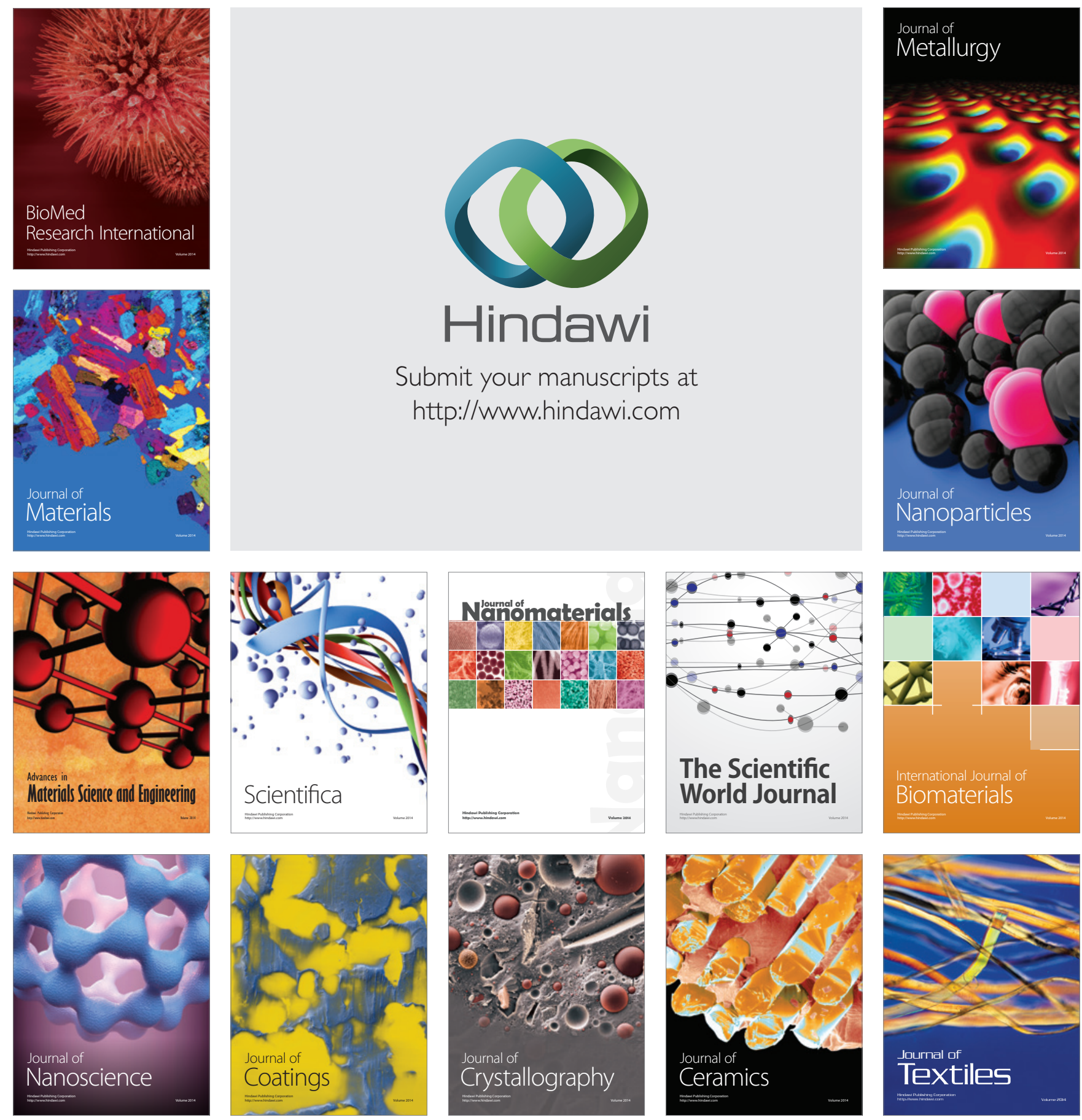